\title{
IImenite/liquid partition coefficients of 26 trace elements determined through ilmenite/clinopyroxene partitioning in garnet pyroxenites
}

\author{
T.Zack ${ }^{1,2}$ and R.Brumm ${ }^{1}$
}

1 Mineralogisch-Petrologisches Institut, Universität Göttingen, Goldschmidtstr.1, 37077 Göttingen, Germany

2 Dept. Earth Sciences, Memorial University of Newfoundland, St.John's, Newfoundland A1B 3X5, Canada

A knowledge of element partitioning $\left(\mathrm{D}_{\mathrm{Min} / \mathrm{L}}\right)$ for as many trace elements as possible in all mantle relevant mineral phases is one prerequisite to a quantitative understanding of magmatic processes. Much effort is spent for this goal in determining these key parameters by conducting experimental studies. This is the most reliable approach but nevertheless time consuming and sometimes problematic in combing results from different studies.

An alternative is to measure mineral/mineral partitioning values in equilibrium parageneses of natural rocks where the D-values of one mineral phase are well known and the other phase partly or completely unknown. The in-situ measurement of the trace element contents by Laser-AblationICP-MS (LAM) in the mineral phases is an ideal way to approach this problem. This method has been described in detail and successfully tested by Zack et al. (1997).

Ilmenite occurs in most magmatic systems only as an accessory phase. Nevertheless, there are a few exceptions where it plays an important role, e.g. it is abundant in many garnet pyroxenite xenoliths, in MARID xenoliths, as ilmenite megacrysts in kimberlites, and as ilmenite bearing cumulates involved in the generation of high-Ti mare basalts on the moon. Here, we present data from two garnet pyroxenite localities.

Despite the widespread occurrence of ilmenite a consistent multielement $D_{\text {IIm/L }}$ set (HFSE, LILE, REE, transition elements) is lacking and compilations of databases used for geochemical modelling have to rely on interpolations and estimations. Therefore, we have measured the trace element contents of five ilmenite/clinopyroxene pairs from Bayuda, Sudan (C59, C42) and Kakanui, New Zealand (K2b, K4, K7) with LAM. These partitioning values can be combined with experimentally determined $\mathrm{D}_{\mathrm{Cpx} / \mathrm{L}}$ values, so that the derivation of $\mathrm{D}_{\mathrm{Ilm} / \mathrm{L}}$ values is straightforward (Table 1, Fig. 1).

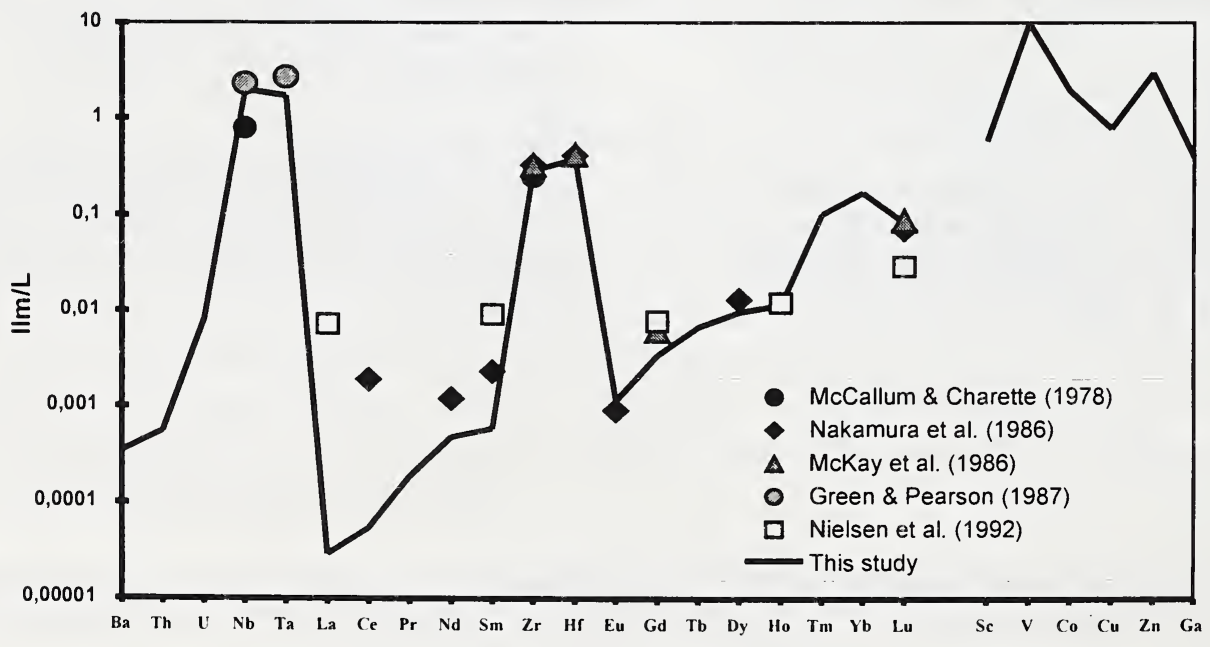

Figure 1. Partition coefficients $D_{I I m / L}$ derived in this study compared to experimental studies. 
Table 1. Major elements (in \%) are measured with EMP and trace elements (in ppm) with $\mathrm{LAM}_{\text {. TiO }}$ is used as an internal standard for all LAM analyses. $\mathrm{D}_{\mathrm{Cpx} / \mathrm{L}}$ values are taken from experimental studies as outlined from Zack et al. (1997). $D_{\mathrm{Ilm} / \mathrm{L}}$ was derived according to the formula $D_{\operatorname{llm} / L}=D_{\operatorname{llm} / \mathrm{Cpx}} * D_{\mathrm{Cpx} / \mathrm{L}}$.

\begin{tabular}{|c|c|c|c|c|c|c|c|c|c|c|c|c|c|}
\hline & \multicolumn{5}{|c|}{ Clinopyroxene } & \multicolumn{5}{|c|}{ Ilmenite } & \multirow[t]{2}{*}{$\mathrm{D}_{\text {CpuLL }}$} & \multirow[t]{2}{*}{$\mathrm{D}_{\mathrm{llm} / \mathrm{Cpx}}$} & \multirow[t]{2}{*}{$\mathrm{D}_{1 \mathrm{~lm} / \mathrm{L}}$} \\
\hline & C59 & $\mathrm{C} 42$ & $\mathrm{~K} 2 \mathrm{~b}$ & K4 & K7 & C59 & $\mathrm{C} 42$ & $\mathrm{~K} 2 \mathrm{~b}$ & K4 & K7 & & & \\
\hline$\overline{\mathrm{SiO}_{2}}$ & 49.21 & 48.82 & 48.08 & 48.10 & 48.43 & 0.02 & 0.01 & 0.04 & 0.01 & 0.01 & & & \\
\hline $\mathrm{TiO}_{2}$ & 1.62 & 1.36 & 1.91 & 1.81 & 1.81 & 42.55 & 43.89 & 51.71 & 51.81 & 51.20 & 0.38 & 29 & 11 \\
\hline $\mathrm{Al}_{2} \mathrm{O}_{3}$ & 8.73 & 8.06 & 8.91 & 9.50 & 8.93 & 1.13 & 0.86 & 0.85 & 0.67 & 0.65 & & & \\
\hline $\mathrm{Cr}_{2} \mathrm{O}_{3}$ & 0.01 & 0.02 & 0.02 & 0.02 & 0.01 & 0.04 & 0.04 & 0.05 & 0.03 & 0.03 & & & \\
\hline $\mathrm{FeO}$ & 6.43 & 6.05 & 7.38 & 7.55 & 8.30 & 49.42 & 45.96 & 37.50 & 38.25 & 39.24 & & & \\
\hline $\mathrm{MnO}$ & 0.05 & 0.03 & 0.06 & 0.07 & 0.11 & 0.14 & 0.20 & 0.13 & 0.17 & 0.17 & & & \\
\hline $\mathrm{MgO}$ & 11.82 & 11.61 & 12.51 & 11.77 & 11.44 & 4.52 & 5.17 & 7.94 & 7.31 & 6.93 & & & \\
\hline $\mathrm{CaO}$ & 19.75 & 21.28 & 17.99 & 19.24 & 17.02 & 0.02 & 0.04 & 0.03 & 0.03 & 0.03 & & & \\
\hline $\mathrm{Na}_{2} \mathrm{O}$ & 1.82 & 1.56 & 1.86 & 1.98 & 2.36 & 0.01 & 0.02 & 0.01 & 0.03 & 0.01 & & & \\
\hline Total & 99.44 & 98.80 & 98.72 & 100.04 & 98.41 & 97.86 & 96.19 & 98.27 & 98.29 & 98.28 & & & \\
\hline $\mathrm{Ba}$ & 0.085 & $<0.02$ & 0.030 & 0.029 & 0.034 & $<0.28$ & 0.051 & 0.014 & $<0.03$ & $<0.03$ & 0.0007 & 0.49 & 0.00034 \\
\hline Th & 0.19 & 0.12 & 0.27 & 0.35 & 0.10 & $<0.06$ & $<0.03$ & $<0.03$ & $<0.01$ & 0.0048 & 0.012 & 0.046 & 0.00055 \\
\hline $\mathrm{U}$ & 0.043 & 0.029 & 0.062 & 0.12 & 0.042 & 0.061 & 0.030 & 0.031 & 0.081 & 0.014 & 0.0103 & 0.79 & 0.0082 \\
\hline $\mathrm{Nb}$ & 0.27 & 0.11 & 0.32 & 0.35 & 0.50 & 50.9 & 37.9 & 86.5 & 78.2 & 130.7 & 0.0077 & 258 & 2.0 \\
\hline $\mathrm{Ta}$ & 0.059 & 0.049 & 0.055 & 0.046 & 0.078 & 3.32 & 3.32 & 6.26 & 4.98 & 7.96 & 0.019 & 90 & 1.7 \\
\hline $\mathrm{La}$ & 4.52 & 3.10 & 3.50 & 4.79 & 3.16 & $<0.02$ & 0.0017 & $<0.01$ & $<0.01$ & $<0.01$ & 0.0536 & 0.00054 & 0.000029 \\
\hline $\mathrm{Ce}$ & 20.2 & 15.6 & 9.89 & 13.1 & 10.6 & 0.0081 & 0.016 & $<0.01$ & 0.0056 & 0.01 & 0.0858 & 0.00063 & 0.000054 \\
\hline $\mathrm{Pr}$ & 3.32 & 2.74 & 1.66 & 1.87 & 1.73 & $<0.01$ & 0.0033 & $<0.01$ & $<0.01$ & 0.0025 & 0.14 & 0.0013 & 0.00019 \\
\hline $\mathrm{Nd}$ & 18.4 & 15.3 & 10.0 & 9.36 & 10.3 & $<0.18$ & 0.068 & 0.010 & 0.014 & 0.034 & 0.1873 & 0.0026 & 0.00048 \\
\hline $\mathrm{Sm}$ & 5.83 & 4.58 & 3.74 & 2.97 & 3.45 & $<0.11$ & $<0.05$ & 0.012 & 0.007 & 0.0022 & 0.291 & 0.0020 & 0.00059 \\
\hline $\mathrm{Zr}$ & 62.3 & 46.9 & 52.1 & 54.8 & 60.1 & 143 & 143 & 109 & 131 & 112 & 0.1234 & 2.34 & 0.29 \\
\hline $\mathrm{Hf}$ & 2.48 & 2.09 & 1.96 & 1.88 & 2.07 & 3.87 & 4.22 & 2.46 & 2.74 & 2.28 & 0.256 & 1.48 & 0.38 \\
\hline $\mathrm{Eu}$ & 2.59 & 1.96 & 1.38 & 1.13 & 1.40 & $<0.03$ & 0.0065 & 0.0077 & 0.0023 & 0.0048 & 0.32 & 0.0036 & 0.0011 \\
\hline Gd & 4.55 & 3.48 & 3.45 & 2.54 & 3.33 & $<0.13$ & $<0.07$ & $<0.10$ & $<0.02$ & 0.028 & 0.4 & 0.0085 & 0.0034 \\
\hline $\mathrm{Tb}$ & 0.59 & 0.45 & 0.48 & 0.32 & 0.50 & $<0.05$ & $<0.01$ & 0.0086 & 0.0054 & 0.0063 & 0.420 & 0.016 & 0.0067 \\
\hline Dy & 2.50 & 1.92 & 2.01 & 1.15 & 2.17 & $<0.09$ & $<0.04$ & $<0.07$ & 0.022 & 0.053 & 0.442 & 0.022 & 0.010 \\
\hline Ho & 0.30 & 0.22 & 0.27 & 0.14 & 0.33 & $<0.02$ & & $<0.01$ & 0.0022 & 0.011 & 0.467 & 0.024 & 0.011 \\
\hline $\mathrm{Tm}$ & 0.050 & 0.029 & 0.035 & 0.011 & 0.062 & $<0.03$ & $<0.01$ & 0.0065 & 0.0029 & $<0.01$ & 0.449 & 0.22 & 0.10 \\
\hline $\mathrm{Yb}$ & 0.18 & 0.12 & 0.14 & 0.070 & 0.31 & $<0.14$ & 0.082 & $<0.04$ & 0.025 & 0.050 & 0.430 & 0.40 & 0.17 \\
\hline $\mathrm{Lu}$ & 0.020 & 0.010 & 0.013 & 0.0044 & 0.033 & $<0.03$ & $<0.04$ & $<0.02$ & $<0.02$ & 0.0064 & 0.433 & 0.19 & 0.084 \\
\hline $\mathrm{Sc}$ & 50.9 & 38.8 & 16.8 & 13.9 & 25.4 & 13.5 & 14.2 & 11.0 & 6.2 & 12.3 & 1.31 & 0.44 & 0.58 \\
\hline V & 586 & 508 & 377 & 390 & 357 & 2871 & 2735 & 1231 & 988 & 815 & 3.1 & 4 & 11 \\
\hline Co & 28.8 & 28.7 & 51.4 & 45.5 & 46.5 & 159 & 154 & 238 & 240 & 214 & 0.38 & 5.1 & 1.9 \\
\hline $\mathrm{Cu}$ & 10.4 & 7.4 & 7.3 & 6.5 & 6.4 & 10.7 & 14.7 & 14.7 & 16.7 & 21.3 & 0.36 & 2.19 & 0.79 \\
\hline $\mathrm{Zn}$ & 28.7 & 25.6 & 35.6 & 72.6 & 79.2 & 132 & 181 & 299 & 430 & 319 & 0.5 & 6.0 & 3.0 \\
\hline $\mathrm{Ga}$ & 13.6 & 12.7 & 20.1 & 25.6 & 21.4 & 7.5 & 9.8 & 10.8 & 11.8 & 7.7 & 0.74 & 0.54 & 0.40 \\
\hline
\end{tabular}

\section{Garnet pyroxenites from Bayuda, Sudan, and Kakanui, New Zealand}

The investigated ilmenite bearing garnet pyroxenites occur in the xenolith suites of the alkaline volcanic centers from Bayuda, Sudan and Kakanui, New Zealand. The parageneses consist of garnet, clinopyroxene, amphibole and up to 20 modal \% of spinel and ilmenite. Textural features (triple junctions) and exceptional major element homogeneity are evidence for equilibrium conditions, making them prime candidates for this type of studies. Despite similar PT-conditions (ca. $17 \mathrm{kbar}, 930^{\circ} \mathrm{C}$; Brumm et al., 1996, Zack et al., 1997) the two localities are distinguishable in different $\mathrm{Fe}^{3+}$ contents, resulting in a remarkably higher hematite component in the Bayuda ilmenites relative to the ilmenites from Kakanui (17-20\% and 5-6\% respectively). In contrast the clinopyroxenes show only a small variation between the two localities (Mg\# 77 vs. 71-75, CaTs 1011 vs. $9-14 \%$ respectively). This allows evaluation of the influence of one crystal chemical variable in the ilmenite structure on partition coefficients. 


\section{Results}

REE: The $D_{\text {IIm/L }}$ values for the middle to heavy REE compare well with the experimental studies of Nakamura et al. (1986, for Eu, Dy and Lu) and McKay et al. (1986, for Gd and Lu). In contrast the values from $\mathrm{La}$ to $\mathrm{Sm}$ deviate considerably from the experimentally determined data of Nakamura et al. (1986) and Nielsen et al. (1992), which may be due to problems with detection limits or contamination in the earlier studies in measuring very low partition coefficients. The extremely low $\mathrm{D}_{\mathrm{IIm} / \mathrm{L}}$ values for the LREE are much better in agreement to crystal site size and bulk modulus considerations where the REE are accommodated on the (Fe, $\mathrm{Mg}$ ) site similar to the behavior of REE in olivine (Beattie et al., 1994).

HFSE: Experimental partition coefficients for $\mathrm{Zr}$ and $\mathrm{Hf}$ (0.33 and 0.41; McKay et al., 1986; Nakamura et al., 1986) are in perfect agreement with the values derived in this study (0.29 and 0.38). It must be stressed that the influence of ilmenite may fractionate the $\mathrm{Zr} / \mathrm{Hf}$ ratio as effectively as clinopyroxene due to the higher $\mathrm{D}_{\mathrm{IIm} / \mathrm{L}}$ despite the smaller difference in $\mathrm{D}_{\mathrm{Zr}}$ and $\mathrm{D}_{\mathrm{Hf}}$ (see Table 1). $\mathrm{Nb}$ and Ta partition coefficients in this study (2.0 and 1.7) agree closely with the results of Green \& Pearson (1987) of 2.3 and 2.7, respectively. This points to a moderately compatible behavior of these elements in ilmenite, in contrast to the results of McCallum \& Charette (1978, 0.8 for $\mathrm{Nb}$ ). The difference of $\mathrm{D}_{\mathrm{IIm} / \mathrm{L}}$ for $\mathrm{Nb}$ and $\mathrm{Ta}$ in our study is not significant, given the variability from measurements of the different samples due to very low concentrations of Ta in clinopyroxene.

Transition elements: There are currently no experimental determinations of $D_{\text {Ilm } / L}$ values for the transition elements for comparison with our results. Crystal site size considerations can also not be used to evaluate our data, suggesting that crystal field effects play an important role for these elements (Beattie et al., 1994). The elements Sc, V, Co, Cu, $\mathrm{Zn}$ and $\mathrm{Ga}$ have ilmenite/clinopyroxene ratios not far removed from 1 , in agreement with the assumptions that these elements will partition into the $(\mathrm{Fe}, \mathrm{Mg})$ site, which is possible both in ilmenite and clinopyroxene. Nevertheless, it is noteworthy that divalent transition elements $(\mathrm{Co}, \mathrm{Cu}, \mathrm{Zn})$ have ilmenite/clinopyroxene ratios of $>1$, whereas trivalent elements $(\mathrm{Sc}, \mathrm{Ga})$ have ratios of $<1$.

The large difference of the hematite content between the Bayuda and Kakanui ilmenites surprisingly do not result in consistently different $\mathrm{D}_{\mathrm{Ilm} / \mathrm{L}}$ values. Calculated values for $\mathrm{U}$ and $\mathrm{Hf}$ are slightly higher in the Bayuda suite than in the Kakanui suite (0.011-0.015 vs $0.004-0.007$ and 0.40 0.52 vs $0.28-0.37$, respectively), values for Ta are slightly lower (1.1-1.3 vs. 1.9-2.1), but for $\mathrm{Nb}$ and $\mathrm{Zr}$ they are in the same range in both suites. Since all these elements should be similarly accommodated in the $\mathrm{Ti}$ site in ilmenite, and since this site is different in Bayuda and Kakanui ilmenites, we feel that the partitioning behavior of ilmenites is not strongly dependent on the hematite content, at least not in the range we investigated $(8-22 \%)$.

\section{References}

Beattie, P., 1994, Systematics and energetics of trace-element partitioning between olivine and silicate melts: Implications for the nature of mineral/melt partitioning: Chemical Geology, 117, p.57-71.

Brumm, R., Zinngrebe, E., Pudlo, D., Abs-Wurmbach, I., and Meyer, H.P., 1996, Geothermobarometry in high Fe ${ }^{3+}$ garnet pyroxenites from Bayuda Main Volcanic Field, Sudan: J. of Conference Abstracts, 1, p.84.

Green, T.H., and N.J. Pearson, 1987, An experimental study of Nb and Ta partitioning between Ti-rich minerals and silicate liquids at high pressure and temperature: Geoch. Cosmoch. Acta, 51, p.55-62.

McKay, G., Wagstaff, J., and S.-R. Yang, 1986, Zr, Hf, and REE partition coefficients for ilmenite and other minerals in high-Ti lunar mare basalts: An experimental study: Proc. $16^{\text {th }}$ Lun. Plan. Sci. Conference, p.D229-D237.

McCallum, M.T., and Charette, M.P., 1978, Zr and Nb partition coefficients: Implications for the genesis of mare basalts, KREEP, and sea floor basalts: Geoch. Cosmoch. Acta, 42, p.859-869.

Nakamura, Y., Fujimaki, H., Nakamura, N., and M. Tatsumoto, 1986, Hf, Zr, and REE partition coefficients between ilmenite and liquid: Implications for lunar petrogenesis: Proc. $16^{\text {th }}$ Lun. Plan. Sci. Conference, p. D239-D250.

Nielsen, R.L., Gallahan, W.E., and F. Newberger, 1992, Experimentally determined mineral-melt partition coefficients for Sc, Y and REE for olivine, orthopyroxene, pigeonite, magnetite and ilmenite: CMP., 110, p.488-499.

Zack, T., Foley, S.F., and G.A. Jenner, 1997, A consistent partition coefficient set for clinopyroxene, amphibole and garnet from laser ablation microprobe analysis of garnet pyroxenites from Kakanui, New Zealand: Neues Jahrbuch Mineralogische Abhandlungen, 172, p.23-41. 